\title{
DESENVOLVIMENTO DO ESTRESSE OCUPACIONAL E SUA INCIDÊNCIA NOS PROFESSORES UNIVERSITÁRIOS DO HUAMBO
}

\author{
Development of occupational stress and its incidence in university professors of \\ Huambo / Desarrollo del estrés ocupacional y su incidencia en los profesores \\ universitarios del Huambo
}

\section{Américo Custódio Hungulo ${ }^{1}$}

\section{RESUMO}

O presente artigo tem como objectivo contribuir na elevação do nível de conhecimento do estresse ocupacional entre professores do ensino superior da província do Huambo. O estresse ocupacional destaca-se a partir dos elementos estressores externos e internos. As doenças com vínculo ocupacional no contexto educacional na província do Huambo, não são encaradas como parte da vida social e científica para a qualidade de vida dos professores. Segundo Farber (1991), a formação do professor enfatiza conteúdos e tecnologia, sendo deficiente a abordagem nas questões de relacionamento interpessoal, relacionamento com alunos, administradores, pais e outros actores sociais. Nesse sentido as transformações sociais ocorrem quando há saúde e trabalho, e por sua vez relacionadas fundamentalmente aos processos de gestão e organização do próprio trabalho. Os resultados derivados do presente estudo permitiram despertar aos professores universitários inqueridos, sobre a necessidade de superação e de fortalecimento do conhecimento do estresse ocupacional, os riscos, e consequências dessa profissão, para o melhor desempenho das suas actividades, assim como o modo de prevenção. Por essa razão, os psicólogos, médicos e profissionais das áreas afins, são chamados a contribuir significativamente para a transformação qualitativa desta temática. A metodologia utilizada baseou-se essencialmente na pesquisa qualitativa, enfatizando o formato de inquérito por questionário, no diálogo aleatório estabelecido com setenta professores de distintas instituições de ensino superior da província do Huambo.

Palavras-chave: Estresse ocupacional, Síndrome de Burnout, Professores universitários, Angola.

Recebido: Outubro $2018 \quad$ Aceitado: Dezembro 2018

\section{RESUMEN}

El presente artículo tiene como objetivo contribuir a elevar los niveles de conocimientos del estrés ocupacional entre profesores de ensenanza superior de la

\footnotetext{
1 Investigador académico; licenciado pela Universidade Agostinho Neto no Instituto Superior de Ciências de Educação - Huambo na opção de Psicologia; Mestre em Psicopedagogia Clínica graduado pela Universidade de León pelo Instituto de Altos Estudos Universitários - Barcelona Espanha. Especialidade em neuropsiquiatria pela área pedagógica do Hosptial Geral do Huambo. Huambo. Angola. Email: ahungulo@gmail.com
} 
província de Huambo. El estrés ocupacional se destaca a partir de los elementos estresores externos e internos. Las enfermedades con vínculo ocupacional en el contexto educacional en la província de Huambo, no son encaradas como parte de la vida social e científica aumentar la calidad de vida de los profesores. Según Farber (1991), la formación del profesor enfatiza contenidos y tecnología, siendo limitado el tratamiento en cuetiones de questiones de relacionamiento interpersonal, relacionamiento com alumnos, administradores, padres y otros actores sociales. En este sentido, las transformaciones sociales ocurren cuando hay salud y trabajo, del mismo modo, relaccionadas fundamentalmente a los procesos de gestión y organización del própio trabajo. Los resultados derivados del presente estudio permitieran despertar a los profesores universitarios encuestados, sobre la necesidad de superación y de fortalecimiento del conocimiento del estrés ocupacional, los riesgos y consecuencias de esa profesión, para el mejor desempeno de sus actividades, bien como el modo de prevención. Por esa razón los psicólogos, médicos y profesionales de áreas similares, son llamados a contribuir significativamente para la transformación cualitativa de esta temática. La metodología utilizada fue esencialmente cualitativa, enfatizando el formato de encuestas, en el diálogo aleatório establecido con setenta profesores de distintas instituciones de ensenanza superior de la província de Huambo.

Palabras-Clave: Estrés ocupacional, Síndrome de Burnout, Profesores universitarios, Angola.

\section{ABSTRACT}

The present article has as objective to contribute in the elevation of the level of knowledge of the occupational stress among teachers of the higher education of the province of Huambo. The occupational stress stands out starting from the elements external and internal stressed. The diseases with occupational bond in the education context in the province of Huambo are not faced as part of the social life and scientific for the quality of the teachers' life. According to Farber (1991), the teacher's formation emphasizes contents and technology, being deficient the approach in the subjects of relationship interpersonal, relationship with students, administrators, parents and other situations. In that sense the social transformations happen when there are health and work, and for time related fundamentally to the administration processes and organization of the own work. The derived results of the present study allowed awakening teachers about the need of superation about it and of invigoration of the knowledge of the occupational stress, the risks, and consequences of that profession, for the best acting of their activities, as well as the prevention way. For such psychologists, doctors and professionals of the similar areas are called for best to contribute in this theme. The approach was through the qualitative research, the inquiry format for questionnaire, for the conversation and presented aleatory to seventy teachers of some higher education institutions in the province of Huambo.

Key - word: Stress occupational, Syndrome of Burnout, university teachers, Angola. 
Desenvolvimento do estresse ocupacional e sua incidência nos professores universitários do Huambo

\section{INTRODUÇÃO}

A profissão de professor, configura-se como uma profissão alvo de muitos factores de estresse devido á elementos psicossociais presentes no seu contexto laboral. O estresse ocupacional destaca-se neste estudo, devido ao impacto negativo que tem causado na saúde e bem-estar dos trabalhadores e sua consequente repercussão no funcionamento das instituições de ensino.

Assim, a Síndrome de Burnout é conotada como uma das principais consequências do estresse ocupacional. Porém, o objectivo deste estudo visa contribuir para elevar o nível de conhecimento do estresse ocupacional entre os professores universitários da província do Huambo. Os resultados obtidos do presente estudo, contribuem a compreender os problemas enfrentados no exercício da profissão, tais como a insatisfação profissional, a falta de produção no local de trabalho, o absentismo, bem como os acidentes de trabalhos.

Constatou-se na amostra conformada por 70 professores universitários, a insuficiente compreensão do estresse ocupacional. Entre as causas que motivaram a elaboração do presente estudo, destacam-se as constantes ocorrências entre os professores, sobre o conhecimento do estresse ocupacional, facto que possibilitou estabelecer a diferença existente entre este, e a síndrome de burnout.

\section{ESTRESSE OCUPACIONAL E A SÍNDROME DE BURNOUT}

O estresse ocupacional é uma desestabilização psicológica e emocional que aparece no ambiente de trabalho.

Segundo Dejours (1987), o estresse ocupacional está associado ao trabalho, como um conjunto de perturbações psicológicas ou sofrimentos psíquicos, relacionados com experiências do contexto laboral.

Cooper et al. (1998) define O estresse ocupacional como sendo um problema negativo, de caracter inadequado de combate às fontes de pressão, e que traz consequências negativas para o indivíduo, tanto no plano mental quanto físico. Consideram que todo o trabalho possui agentes potencialmente estressantes comum a todas as ocupações profissionais. É precisamente um conceito em que a percepção, a subjectivdade individual, como componentes da personalidade façam 
ressonância nas discussões entre especialistas no que tange às reflexões jurídicolaborais do estresse como enfermidade profissional ou laboral. Por conseguinte, entrarão em jogo valores culturais, experiências, personalidade, situação social, graus de objectividade e de subjectividade do indivíduo para perceber ou atribuir como uma determinada situação o que pode responder factores psicobiológicos com os quais o organismo conta. Esses problemas podem ser por medo de fracassar, cansaço físico e emocional, por insuficiente apoio, sensação de ser mal interpretado, orientação ou gerenciamento inadequado de seus superiores.

Neste sentido, Selye (1952, citado por Lipp, 1996), o processo de estresse desencadeia-se em três fases: alerta, resistência e exaustão. $O$ referido autor argumenta que o estresse é individual e deve ser considerado em seus aspectos físicos e psicológicos, logo se houver persistência do estímulo estressor, o organismo entra em uma fase de esgotamento.

Entre os factores que contribuem para o estresse ocupacional destacam-se: O medo de fracassar; longa jornada de trabalho; trabalho com alta concentração mental; responsabilidade mal delegada; salário; trabalho monótono; bloqueio de carreira; falta de motivação entre outros. Por isso é que existem características de resistências de pessoas com estresse ocupacional, que segundo o pensamento lógico, há tipo de personalidade que intensificam os efeitos dos estressores no trabalho, tal como o caso de agressividade e a competitividade, assim como a necessidade de obter sucesso. O estresse implica uma reação complexa nos níveis biopsicossocial. Existem sintomas fisiológicos, psicológicos e comportamentais indicativos de reação ao estresse.

Sabe-se de antemão que a alteração na bioquímica sanguínea, sintomas gastrintestinais (como gastrite e úlcera), insatisfação com o trabalho, fadiga e depressão, diminuição da confiança, baixa auto - estima, apatia emocional, estado afectivo mais intenso como frustração, decadência por exaustação são reacções biopsicossocial que se deve ter em conta uma vez que o estresse ocupacional afecta a qualidade da prestação de serviço o que implicará se assim for o caso um trabalho preventivo. O estresse ocupacional surge quando as exigências do trabalho não correspondem às capacidades, aos recursos ou às necessidades do 
Desenvolvimento do estresse ocupacional e sua incidência nos professores universitários do Huambo

trabalhador. Os possíveis factores estressantes existentes no trabalho, englobam aspectos físicos, aspectos da organização e de conteúdo do trabalho e que de acordo com Lipp (2010) pode se entender que a sobrecarga e as pressões excessivas por tempo e resultados no trabalho, em um mundo competitivo ao extremo, são as grandes causadoras do estresse laboral.

Porém, Maslach et al. (2001) Assinala que o esgotamento emocional representa a dimensão de tensão básica da Síndrome de Burnout; a despersonalização expressa o contexto interpessoal onde se desenvolve o trabalho do sujeito, e a diminuição das conquistas pessoais, representa a auto - avaliação que o indivíduo realiza de seu desempenho ocupacional e pessoal.

Por sua vez Farber (1991) divide as manifestações do burnout em professores com sintomas individuais e profissionais, destacando, entretanto, que estas questões são de difíceis generalizações e descrições universais. Na linha do pensamento do mesmo autor, os professores sentem-se emocional e fisicamente exaustos, estão frequentemente irritados, ansiosos, com raiva ou tristes. As frustrações emocionais peculiares a este fenómeno podem levar a sintomas psicossomáticos como insônia, úlceras, dores de cabeça e hipertensão, além de abuso no uso de álcool e medicamentos, incrementando problemas familiares e conflitos sociais.

Gomes e Quintão (2011) dizem tratar-se de uma síndrome com conotações afectivas negativas que afecta os trabalhadores a diferentes níveis: pessoal, social e laboral.

\section{PROFESSORES UNIVERSITÁRIOS E O ESTRESSE OCUPACIONAL}

Em geral, os professores universitários se sentem emocional e fisicamente exaustos, ansiosos, por causa da especificidade do seu trabalho que é de ensinar e educar para o crescimento e desenvolvimento pessoal, social e do país em geral (Farber, 1991).

As consequências do estresse ocupacional em professores universitários podem se repercutir na organização escolar assim como na relação com os alunos. 
Para Lipp (2002), o estresse ocupacional constitui uma experiência desagradável associada a sentimentos de hostilidade, tensão, ansiedade, frustração e depressão, desencadeados por estressores, localizados no ambiente de trabalho. A posição social de professores sofre muitas críticas e, raramente, é reconhecida por seu sucesso, que por conseguinte é cobrado em seus fracassos. Mesmo que esta seja uma tendência de todas as profissões, nenhuma categoria tem sido tão avaliada e cobrada pela população, em geral nas últimas duas décadas, como a de professor. Os professores universitários precisam estar capacitados de conhecimentos diversos, tais como o conhecimento pedagógico e científico, e possuir uma sensibilidade e criatividade que thes permitam reagir as situações e obstáculos da docência.

Segundo Farber (1991) diz que o estresse e o burnout não são fenómenos novos, mas o que lhes põem em destaque são os sentimentos relacionados ao trabalho a esses mesmos fenómenos. Quando o professor universitário possui um alto nível de burnout, principalmente da dimensão de despersonalização, o professorado deixa de ser um diálogo entre alunos e professores e passa a ser realizada de uma maneira imparcial e burocrática, onde ambos ocultam seus conhecimentos e apenas se cumpre o compromisso de se estar na instituição de ensino, afectando directamente na qualidade de ensino (Álvarez, 2012).

Os profissionais que lidam directamente com pessoas são os mais afectados pela síndrome, pois estão sujeitos a um maior envolvimento emocional, o que acarrecta uma sobrecarga emocional e mental. Neste contexto, uma das profissões mais atingida por esta patologia é a de professorado (Carlotto, 2011).

\section{ENSINO SUPERIOR E A CAUSA DO ESTRESSE OCUPACIONAL}

O estresse no trabalho repercute na vida social dos funcionários, que muitas vezes não têm tempo, devido à sobrecarga de trabalho, nem disposição, devido ao cansaço, de sair, se distrair, ter alguns momentos de lazer. $O$ ensino superior é o nível mais elevado de graduação académica que possibilita um indivíduo a ser considerado apto no exercício de suas funções actuais ou posteriores. Por esta 
Desenvolvimento do estresse ocupacional e sua incidência nos professores universitários do Huambo

razão os professores universitários devem estar comprometidos com a sua profissão, de modo que venham a corresponder com as expectativas da instituição de ensino e formação para que se possa alcançar os objectivos preconizados pelo currículo académico - profissional.

Lipp (2007) diz que a maior parte do tempo das pessoas é dedicada à sua profissão, com ritmos de trabalho intensos, exigências de altos níveis de atenção e concentração, para desempenhar também sob pressão actividades no seu dia-adia, podendo utilizar novas tecnologias, mas que pode resultar em desgaste, tensão, insatisfação e esgotamento.

O relato de uma conversa mantida com professores do ensino superior, das distintas unidades académicas existentes na província do Huambo - Angola, no âmbito das investigações, nos fez concluir que segundo o pensamento logico científico o estresse ocupacional entre professores do ensino superior na província do Huambo, recai em dias em que o profissional «dá sua aula» que dura 50 minutos por cada tempo, desde o $1^{\circ}$ tempo até ao último tempo, e principalmente em períodos de provas de frequências, exames, e exames de recurso. Assim, o mesmo período é marcado por vigilância às provas, pontualidade e assiduidade, esclarecimento do conteúdo a ser avaliado, assinatura do livro de ponto e correcção das provas. Por outra, toma-se nota que as colaborações dos professores universitários em duas (2), ou em três (3) instituições de ensino superior, também ocupa uma das causas do estresse ocupacional. Em seguida, o número elevado de estudantes nas turmas, estudantes que perguntam assuntos fora da matéria, o barulho que surge durante a aula por parte dos mesmos, bem como outras ocorrências inerente ao ambiente de trabalho também contribuem no surgimento das causas do estresse ocupacional entre professores do ensino superior. Logo, diante destas situações nem todos professores se apercebem de estarem a concorrer ao estresse ocupacional que é o causador de ligeiras dores de cabeça, mal-estar, indisposições dentre outros. 


\section{GRÁFICO 1. Percurso do estresse ocupacional}

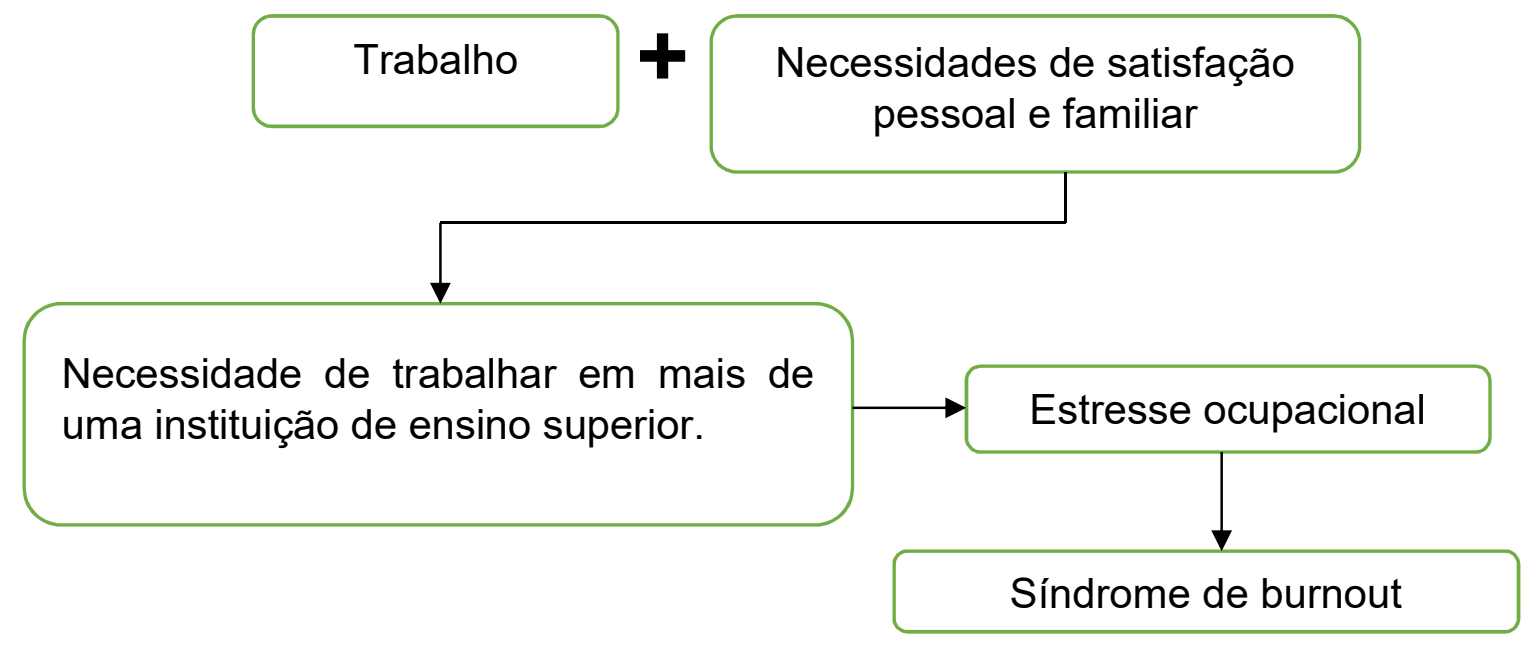

Fonte: Elaboração própria

O estresse ocupacional surgi no ambiente laboral de diversas maneiras e para tal podemos associar as necessidades que por sua vez podem obrigar o profissional a trabalhar em mais de uma Instituição de ensino superior o que pode provocar o estresse ocupacional pelo facto de não corresponder com os objectivos ideais de vida o que também pode desembocar em síndrome de burnout. Logo, trabalhar é um bem necessário que cria riqueza mas que deve ser de maneira a proporcionar saúde física e mental. O professorado exige muito dos profissionais ou seja uma entrega total na transmissão dos conhecimentos; o que torna dispendioso trabalhar em mais de uma instituição de ensino superior. Vejamos que um professor deve preparar suas aulas de forma planificada e essa planificação leva o seu tempo que pode ser mais que o tempo de duração de uma aula só ou seja as planificações de aulas levam mais tempo do que a duração das aulas em si e quando não acontece o professor parte para o improviso o que não é bom. Deste modo o tempo fica cada vez mais escasso e insuficiente além de outras situações envolventes como o os meios de ensino, metodologia, o próprio material didático para planificar as aulas e dai pode haver condições criadas para o aparecimento do estresse ocupacional, que de um modo o professor começa a ter princípio de esgotamento físico e emocional e despersonalização o que se traduziria em síndrome de Burnout. 


\section{UM OLHAR NA PREVENÇÃO DO ESTRESSE OCUPACIONAL}

É tarefa de todos os trabalhadores velar pela saúde mental que é um bem valorizado em todas as sociedades, porque proporciona sinergia necessária para que haja um clima de trabalho salutar, relações humanas adequadas bem como um funcionamento eficaz das organizações, instituições, empresas entre outros. Entende-se que pode-se prevenir o estresse ocupacional evitando assuntos muito pessoais, cumprimentar as pessoas com cordialidade, ter uma postura digna, ser cooperativo, ser grato e retirar-se no ambiente de trabalho que fomenta discórdia.

Autores há que defendem que deve-se considerar o indivíduo, o grupo e o ambiente como componentes de um sistema no qual cada um é afectado pelos demais, de várias formas. Por toda via o comportamento das pessoas afecta e é afectado pelo ambiente físico e a cultura no local de trabalho, segundo Huffman (2003).

Outras propostas de intervenção têm tratado de desenvolver um formato amplo e global que possa atender aos diferentes componentes da síndrome. A redução do estresse tem como propósito prevenir os efeitos nocivos da tensão e do estresse emocional através de práticas que capacitem as pessoas a estabelecerem uma nova maneira de vivenciar as pressões e os desafios do dia-a-dia.

Segundo Varella (2011) aconselha que é o próprio profissional que tem que avaliar se as condições de trabalho têm interferência em sua qualidade de vida, trazendo estresse e prejudicando sua saúde física e mental. O mesmo autor relata que o trabalhador também deve avaliar se há a possibilidade de propor nova dinâmica para sua rotina e actividades diárias e também para seus objectivos profissionais na empresa.

Aguiar (2010), sua experiência e convívio com professores, Ihe possibilitou descrever algumas considerações a cerca da profissão, em especial, sobre aspecto que podem provocar estresse, como a insegurança de emprego, a indefinição de suas reais responsabilidades quanto professores, pressão do tempo em realizar diversas actividades em curto prazo de tempo, divergência entre papel de professor 
e educador na sala de aula, dificuldade de progressão na carreira, falta de autonomia, e conflitos oriundos da relação entre trabalho - família, pois há uma considerável dificuldade em administrar psicologicamente a inter - relação existente entre esses dois sistemas na vida do professor, principalmente quando este é do sexo feminino.

\section{METODOLOGIA}

Para a elaboração do presente artigo, se recorreu a uma pesquisa de abordagem qualitativa para se aferir o nível de conhecimento sobre o estresse ocupacional entre os professores universitários do Huambo - Angola. Segundo Chizzotti (1998 citado por ACAFE, 2007, p.10):

A abordagem qualitativa parte do fundamento de que há uma relação dinâmica entre o mundo real e o sujeito [...] O conhecimento não se restringe a um rol de dados isolados, ligados apenas por uma teoria explicativa, o objecto não é um dado inerte e neutro; está possuído de significados e relações que sujeitos concretos criam em suas ações.

Nesse sentido, foi imprescindível argumentar a sua pertinência devido ao limitado enfoque do estresse ocupacional em espaços de discussão académica e científica.

\section{PROCEDIMENTOS}

A pesquisa foi realizada em distintas Instituições de Ensino Superior (IES) públicas e privadas existentes na província do Huambo, recorrendo a técnica da conversação com os respetivos professores, visando melhorar o nível de compreensão que possuem sobre o conhecimento do estresse ocupacional. Para o efeito, aplicou-se o inquérito por questionário a um universo de 90 professores universitários, dos quais, 70 selecionou-se como amostra, mediante a técnica de amostragem aleatória simples, (Tabela 1). 
Tabela 1. Amostra das distintas Instituições de Ensino Superior (IES) públicas e privadas existentes na província do Huambo

\begin{tabular}{|c|c|c|c|}
\hline IES públicas & Amostra & IES privadas & Amostra \\
\hline $\begin{array}{l}\text { Universidade José Eduardo } \\
\text { dos Santos (UJES) }\end{array}$ & 4 & $\begin{array}{l}\text { Instituto Superior Politécnico } \\
\text { Lusíada Huambo (ISPLH) }\end{array}$ & 8 \\
\hline $\begin{array}{l}\text { Instituto Superior de Ciências } \\
\text { de Educação do Huambo } \\
\text { (ISCED) }\end{array}$ & 6 & $\begin{array}{l}\text { Instituto Superior Politécnico Sol } \\
\text { Nascente Huambo (ISPSN) }\end{array}$ & 11 \\
\hline $\begin{array}{l}\text { Instituto Superior Politécnico } \\
\text { do Huambo (ISPH) }\end{array}$ & 6 & $\begin{array}{l}\text { Instituto Superior Politécnico de } \\
\text { Humanidade e Tecnologia Ekuikui } \\
\text { II }\end{array}$ & 7 \\
\hline $\begin{array}{l}\text { Faculdade de Direito Huambo } \\
\text { (Universidade José Eduardo } \\
\text { dos Santos -UJES) }\end{array}$ & 5 & $\begin{array}{l}\text { Instituto Superior Politécnico } \\
\text { Católico do Huambo }\end{array}$ & 4 \\
\hline $\begin{array}{l}\text { Faculdade de Economia } \\
\text { Huambo (UJES) }\end{array}$ & 7 & & \\
\hline $\begin{array}{l}\text { Faculdade de Agronomia } \\
\text { Huambo (UJES) }\end{array}$ & 4 & & \\
\hline $\begin{array}{l}\text { Faculdade de Medicina } \\
\text { Veterinária Huambo (UJES) }\end{array}$ & 4 & & \\
\hline $\begin{array}{l}\text { Faculdade de Medicina } \\
\text { Humana Huambo (UJES) }\end{array}$ & 4 & & \\
\hline \begin{tabular}{l|l} 
Total & \\
\end{tabular} & 40 & 4 & 30 \\
\hline
\end{tabular}

Fonte: Elaboração própria

\section{DISCUSSÃO E ANÁLISE DOS RESULTADOS}

Os professores universitários estimam pela iniciativa de uma investigação quanto ao estresse ocupacional, visto que na sociedade de hoje precisa-se abordar cada vez mais para que haja cuidado com as demandas existentes nos locais de trabalho quanto a saúde mental e em particular ao estresse ocupacional. Levou-se em consideração a sua existência, conhecimento, prevenção, bem como as suas consequências para que haja aprimoramento ao desenvolvimento através da força de trabalho (homem) da sociedade e do país. Nesse processo levou-se em consideração os diferentes pontos de vista do diálogo mantido entre os autores e os diferentes profissionais da área, devido a necessidade de corroboração dos resultados. A correcta aplicação dos instrumentos de recolha de dados possibilitou aferir o nível de conhecimento que os professores do ensino superior do Huambo Angola têm sobre o estresse ocupacional, as causas que o originam, o modo de 
prevenção, bem como os espaços adequados para procurar ajuda profissional. O estudo permitiu que os professores despertassem daquilo que lhes aflige e que têm sido posto em segundo plano nas suas vidas profissionais.

A fundamentação teórica apresentada faz sentido com as práticas das ocorrências profissionais dos professores universitários da província do Huambo. Isto quer dizer que os teóricos ao retratarem sobre o estresse ocupacional bem como as suas manifestações na vida laboral e profissional frisaram aspectos proeminentes e não só que no decorrer da nossa investigação foi possível constatarmos que a fundamentação teórica foi comprovada na prática. De acordo com a aplicação do inquérito por questionário aos professores universitários da província do Huambo; inquérito este que as suas primeiras perguntas retratavam sobre perguntas sobre a personalidade, a seguir aspectos do fórum cognitivos e por último aspectos que têm a ver com a vida social e organizacional.

$\checkmark$ O indicador da existência do estresse ocupacional entre os profissionais deveuse das frequências das respostas de cada pergunta.

$\checkmark$ Portanto o factor de produção (trabalho) é levado de antemão com muita estima e consideração por parte dos profissionais, sabendo que ai pode ser a fonte para que se tenha uma vida com o menor custo de sofrimento.

$\checkmark$ O trabalho do professor exige esforço, estudo, pesquisa constante, preparação de aulas e correcções de provas.

$\checkmark$ A conotação da falta de conhecimento profundo do estresse ocupacional entre os profissionais motivou procurar focar o nível de conhecimento do estresse ocupacional entre professores universitários da província do Huambo.

$\checkmark$ Para tal a conversa mantida com os professores universitários foi possível perceber que o facto de trabalharem em mais de uma instituição de ensino superior é para poderem suprir na íntegra as suas necessidades de vida, desde o ponto de vista do factor riqueza material o que pode acarrectar consequências advindas do ambiente de trabalho.

$\checkmark$ Portanto empregou-se $o$ inquérito por questionário aos professores universitários onde foi possível concretizar e afirmar a parte teórica deste artigo 
Desenvolvimento do estresse ocupacional e sua incidência nos professores universitários do Huambo

através dos objectivos traçados, o que fez reflectir e repensar a vida laboral dos professores universitários da província do Huambo.

\section{CONCLUSÕES}

De acordo com o estudo realizado, obtiveram-se os seguintes resultados:

- Se viabilizou a compreensão de que a problemática relacionada ao estresse ocupacional, carece de mais estudos contextualizados à realidade angolana, por formas a contribuir para o seu fortalecimento.

- Os professores inqueridos foram unânimes em revelar que possuem dificuldades em identificar com precisão, os elementos que provocam o estresse no ambiente laboral.

- Constatou-se durante as provas de frequência e de exames, o esgotamento físico e mental de alguns professores, pelo facto de terem excessivas cargas laborais noutras instituições congéneres, colocando-os em evidentes situações de estresse ocupacional.

- Observou-se o desconhecimento das consequências do estresse ocupacional e a sua implicação na qualidade de vida dos professores.

- Constatou-se nos professores inqueridos, dificuldades em diferenciar a profissão do psicólogo e a do psiquiatra, com fundamentos científicos.

- Apesar de os professores inqueridos terem um conhecimento profundo sobre as ciências psicológicas, ignoram as doenças deste fórum, sobretudo os sinais e sintomas característico do estresse ocupacional.

\section{BIBLIOGRAFIA}

Associação Catarinense das Fundações Educacionais (ACAFE, 2007). Metodologia da pesquisa. Unidade 3. Florianópoli. Brasil.

Álvarez; Carla C. Botero (2012). Riesgo psicosocial intralaboral y "burnout" en docentes universitarios de algunos países latino-americanos. Cuadernos de Administración Universidad del Valle, v. 28, n, 48, Colombia (Pp. 177132).

Aguiar, Aljucy Martins da Rocha (2010). O estresse ocupacional do professor do ensino superior: a relação entre os sintomas de estresse e a atividade docente em duas Instituições de Ensino Superior da cidade de Teresina-PI. 
Tese de Mestrado. Mestrado em Educação no curso de Mestrado em Ciências da Educação. Universidade Lusófona de Humanidades e Tecnologias. Portugal.

Carlotto, Mary Sandra (2011). Síndrome de Burnout em Professores: Prevalência e Fatores Associados. Psicologia: Teoria e Pesquisa, v. 27, n. 4, Brasil (Pp. 403-410).

Cooper, Cary; Cooper, Rachel; e Eaker, Lynn H. (1998). Living with stress. Penguin Books. Inglaterra.

Dejours, Crhistopher (1987). A loucura do trabalho - estudo de psicologia do trabalho. Boré /Cortez. Brasil.

Farber, Barry. A. (1991). Crisis in education. Stress and burnout in the American teacher, Jossey-Bass Inc. EUA.

Gomes, Ana Paula Rodrigues e Quintao; Sonia dos Reis (2011). Burnout, satisfação com a vida, depressão e carga horária em professores. Análise. Psicológica, v.29 n.2, Portugal, (Pp. 335-344).

Huffman, Karen (2003). Psicologia. Atlas. Brasil.

Lipp, Marilda Novaes (1996). Stress: Conceitos básicos. Em M. Lipp (Org.). Pesquisas sobre stress no Brasil: Saúde, ocupações e grupos de risco. Papirus. Brasil.

Lipp, Marilda Novaes (2002). O estresse do professor. Papirus. Brasil. Lipp, Marilda Novaes (2007). Controle do estresse e pressão arterial sistêmica. Ver. Bras. de Hipertensão, Campinas, v. 14, Brasil (Pp. 89-93).

Lipp, Marilda Novaes (2010). Stress na atualidade: qualidade de vida na família e no trabalho. Disponível em: http://www.estresse.com.br/publicacoes/stressna-atualidade-qualidade-de-vida-na-familia-e-no-trabalho/. Acesso em: 22/06/2018.

Maslach, Christina; Schaufeli, Wilma.B. e Leiter, Michael. P. (2001). Job burnout. Annual Review Psychology, 52, EUA. (Pp. 397-422).

Selye, Hans (1952). The story of the adaptacion syndrome. Acta. Canada.

Varella, María (2011). Síndrome de Burnout. Disponível em:

http://drauziovarella.com.br/letras/b/sindrome-de-burnout/. Acesso em: 02/05/2018. 